\title{
RESOLUTION ON “REGISTRATION OF ALL MATERNAL DEATHS"
}

Reviewed and approved by FIGO Executive Board - June 2006 and adopted by the FIGO General Assembly on 7th November 2006. http://www.figo.org/initiatives_maternal_deaths.asp

Recalling that The Millennium declaration in 2000 set out Millennium Development Goals that include a reduction of three quarters in maternal mortality by 2015 .

Recognizing that approximately 36 million women who give birth are not officially registered.

Recognizing that it is difficult to measure progress in maternal mortality ${ }^{*}$ when there is no consistent, sustainable registration system in place in many countries.

Recognizing that if women are valued by society their deaths should be counted in a meaningful way that will inform how other such deaths could be prevented. Such registration serves different purposes in the hospital setting, where regular reviews can occur, than in the community, where methodology may vary including data acquired by census.

Recognizing that the purpose of such data collection is to improve the lives of women and to decrease the causes of unacceptably high maternal mortality rates in many member countries.

Recognizing that registration of maternal mortality in isolation will not bring about the required changes to prevent women from dying. Analysis of the data and provision of a health care system which is adequately resourced and is where skilled health care professional are available is essential. Policy changes may also be required.

Recalling that the right to life is of the pregnant woman is already recognized in national laws, international human rights documents, and other consensus documents.

Re-affirming that women's health is often compromised not by lack of medical knowledge, but by infringements on women's human rights.

Noting with satisfaction the progress reports of the FIGO Committee on Safe motherhood and Newborn Health and the committee on Women's Sexual and Reproductive Rights and the success of some low and middle income countries in reducing maternal mortality.

Affirming that improvements in women's health worldwide require the advocacy and action of Obstetrician/Gynaecologists.

Acknowledging that Obstetricians and Gynaecologists are obligated by the special professional privileges granted to them by nations and societies, as well as their unique knowledge, to promote and protect women's health in their individual and professional encounters.

The FIGO General Assembly:

Confirms its commitment to continue to collaborate with other organizations at the national, regional and international level, including the United Nations System, to reduce maternal mortality.

Calls on FIGO member societies to:

Work with health facilities to ensure consistent registration and confidential review of all maternal deaths for the purposes of decreasing maternal mortality and improvement of quality of care, by identifying system-based problems and resource based problems; data from such reviews can be used to advocate for additional resources.

Urge Ministries of Health and work with them as well as others, including medical schools, to achieve universal registration/reporting of maternal death.

Maternal mortality: According to the Tenth International Classification of Diseases, a maternal death is defined as "the death of a woman while pregnant or within 42 days of termination of pregnancy, irrespective of the duration and the site of the pregnancy, from any cause related to or aggravated by the pregnancy or its management, but not from accidental or incidental causes." 